\title{
Efficacy and Safety Profile of Extended Release Tolterodine in Symptomatic Overactive Bladder
}

\author{
Md Mofizur Rahman ${ }^{1 *}$ \\ AKM Anwarul Islam² \\ Hasan Md, Abdur Rouf ${ }^{3}$ \\ SAMS Golam Kibria ${ }^{2}$
}

${ }^{1}$ Department of Urology

Chittagong Medical College

Chittagong, Bangladesh.

${ }^{2}$ Department of Urology

Bangabandhu Seikh Mujib Medical University Dhaka, Bangladesh.

${ }^{3}$ Department of Surgery

Chittagong Medical College

Chittagong, Bangladesh.
*Correspondence to:

Dr. Md. Mofizur Rahman

Assistant Professor

Department of Urology

Chittagong Medical College

Chittagong, Bangladesh.

Mobile : +8801823050720

Email : uromofiz@yahoo.com

\begin{abstract}
Background: Overactive Bladder (OAB) is a debilitating medical condition having the symptoms of urinary frequency and urgency with or without urge incontinence. Tolterodine was the first drug developed specifically for the treatment of OAB. It is a competitive muscarinic antagonist that exhibits similar affinities for muscarinic receptor subtypes $M_{1}$ to $M_{3}$. Tolterodine may be a more target specific drug that possesses stronger selectivity for the urinary bladder than for the salivary glands. In a pilot study in healthy volunteers, tolterodine was well-tolerated and showed greater function than on salivation. Objectives: To study the efficacy of tolterodine (ER) in relieving symptoms of overactive bladder with its adverse effects to determine the safety of the drug. Methods: This study was conducted at the Department of Urology, Chittagong Medical College Hospital, Chittagong, Bangladesh, from March, 2014 to June, 2015. Purposive sampling was done. Bladder diary was used for evaluating the symptoms of the patient during baseline and 08 weeks follow up. Perceived level of benefit of the patients was assessed and graded using Likert scale. Data analysis was conducted by SPSS version-21. Results: Out of 80 patients, 19 (23.75\%) were male and $62(76.25 \%)$ were female with a male: female ratio 1:3.2. The study revealed that the most of the patients, $48(60.0 \%)$ were subjected to much benefit followed by $23(28.75 \%)$ patients experienced little benefit and $09(11.25 \%)$ patients with no benefit from the treatment. Conclusion: With mild form of side effects tolterodine showed a significant level of efficacy on overactive bladder.
\end{abstract}

Key words: Overactive bladder; Bladder diary; Tolterodine.

\section{INTRODUCTION}

Overactive Bladder $(\mathrm{OAB})$ is a debilitating medical condition having the symptoms of urinary frequency and urgency with or without urge incontinence in the absence of local pathologic or metabolic factors that would account for these symptoms ${ }^{1}$. Although the etiology of $\mathrm{OAB}$ is poorly understood, it has been suggested that nerves and urothelium may play an important role in its pathogenesis. Over activity of the detrusor muscle either from idiopathic or neurogenic such as stroke, spinal cord injury, Parkinson's Disease (PD) and Multiple Sclerosis (MS) and that explains the reason behind the hypothesis of the CNS involvement in OAB pathogenesis ${ }^{2}$. Here we concerned only about the idiopathic causes of OAB.

An overactive bladder is characterized by the urinary symptoms of frequency, urgency and urges incontinence as a result of involuntary detrusor contractions during bladder filling. Such contractions are predominantly under the control of parasympathetic nervous system. Acetylcholine released from the parasympathetic nerve endings activates the $\mathrm{M}_{3}$ muscarinic receptors on detrusor smooth muscles and modulates bladder contractility. OAB frequently follows chronic courses that necessitate lifelong treatment. When compared to other conditions known to negatively affect quality of life such as diabetes major depression and multiple sclerosis the impact of $\mathrm{OAB}$ is comparable or even higher. Furthermore there is financial burden on individuals, families and the government ${ }^{3,4}$. 
Lifestyle modification and behavioral therapy is recommended first line for $\mathrm{OAB}^{5}$. This begins with avoiding or limiting foods medications that can exacerbate symptoms. Alcohol caffeine, diuretics, narcotics, anti-depressives and antihistamines can all exacerbate OAB. Various behavioral techniques (e g. 'Kegel' exercises bladder training and biofeedback) that aim at strengthening or retaining the bladder can reduce and adequately control symptoms in mild cases of $\mathrm{OAB}^{6}$. Drug therapy is considered for patients who have persistent symptoms despite behavioral therapy.

Tolterodine was the first drug developed specifically for the treatment of OAB. It is a competitive muscarinic antagonist that exhibits similar affinities for muscarinic receptor subtypes $M_{1}$ to $M_{3}$. Tolterodine may be a more target specific drug that possesses stronger selectivity for the urinary bladder than for the salivary glands ${ }^{7}$. In a pilot study in healthy volunteers, tolterodine was well-tolerated and showed greater function than on salivation ${ }^{8}$.

The half-life of tolterodine (ER) is approximately 12 hours. Progression to peak therapeutic action is rapid. In phase I clinical trials with healthy volunteers, tolterodine exerted a marked inhibitory effect on bladder function within two hours after a single oral dose ${ }^{9}$. However, clinically noticeable decreases in voiding frequency and incontinence episodes do not occur immediately when behavioral aspects of patients are taken into account. Patients achieve approximately $70 \%$ of the maximum effects within 2 weeks of treatment initiation. Optimal relief of OAB symptoms is achieved after 8 weeks of treatment ${ }^{10,11}$. Clinical response is sustained for at least a year in patients who are compliant and continue to take the medication $^{12}$. The incidence of adverse effects is dose - related for tolterodine. Dry mouth was the most common side effect occurring in $50 \%$ of tolterodine related patients and $21 \%$ placebo group ${ }^{13,14,15}$.

This study was conducted to find out efficacy of tolterodine (ER) to relieve symptoms of overactive bladder. The result was focused on the objective evidence of efficacy of tolterodine (ER) to increase function, decrease symptoms and also observed the subjective sense of improvement of clinical symptoms in the management of symptomatic overactive bladder. This study has also evaluated the tolerability of tolterodine (ER) with the foci on the number and degree of severity of adverse effects.

\section{MATERIALS AND METHODS}

The study was designed as an observational study to evaluate the efficacy and safety of Extended Release (ER) Tolterodine in symptomatic overactive bladder. The study was conducted in Department of Urology, Chittagong Medical College Hospital $(\mathrm{CMCH})$ and Chittagong from March 2014 to June 2015. 89 patients diagnosed with symptomatic overactive bladder were selected consecutively according to selection criteria from the patients attending Urology OPD of Chittagong Medical College Hospital with symptomatic overactive bladder. In the course of time 09 patients were lost to follow up.
A detailed data sheet was completed for each patient that including particulars of the patients, history, results of physical examinations and relevant baseline investigations .During history taking \& physical examinations the patients were examined for their general condition. All systems were carefully examined with special attention to urogenital system. During evaluation of urogenital system presence of pain, haematuria, renal stone, urethral stricture, meatal stenosis or urinary tract infection was excluded or detected. After completion of baseline clinical evaluation and investigations, Tolterodine (ER) $4 \mathrm{mg}$ once daily orally was given for 08 weeks. During follow up visit at 8 week patients were again underwent physical examination and bladder urinary variables like number of maturations per day, episodes of incontinence per day and amount of voide volume per micturition $(\mathrm{ml})$ were assessed and the side effects of the drugs were recorded. On $2^{\text {nd }}$ visit, patient's perception of treatment benefit was also evaluated.

\section{Inclusion criteria}

Symptomatic OAB having

i) Age 18 years or more

ii) Urgency or urge incontinence (At least 01 incontinence episode $/ 24$ hours).

\section{Exclusion criteria}

i) Require intermittent catheterization or an indwelling catheter ii) Recurrent or acute UTI

iii) Patients with congestive cardiac failure, severe liver and renal diseases

iv) Presence of contraindicatications for antimuscarinic agents v) Pregnant or lactating women.

\section{RESULTS}

Out of 80 patients, 19 (23.75\%) were male and 62 (76.25\%) were female. Male female ratio was 1:3.2. The age of males were (Mean- $50.89 \pm$ SD- 8.445) and age of females were (Mean- $50.89 \pm$ SD- 8.445) with an overall value as (Mean$51.54 \pm$ SD- 7.89) with no statistically significant difference (Table 1).

On clinical examination mean heart rate was found 86 per minute and SD was 11.5 per minute. Systolic blood pressure found to be (Mean- $132.75 \mathrm{~mm}$ of $\mathrm{Hg} \pm \mathrm{SD}-16.25 \mathrm{~mm}$ of $\mathrm{Hg}$ ) and diastolic blood pressure was (Mean- $81.30 \mathrm{~mm}$ of $\mathrm{Hg} \pm$ SD- $10.52 \mathrm{~mm}$ of $\mathrm{Hg}$ ) (Table 2).

The numbers of micturition per day were (Mean- $12.2 \pm$ SD1.87) during baseline in comparison to (Mean- $8.74 \pm$ SD-0.78) after 08 weeks with drug and mean decrease of micturition per day was $3.46 \pm 1.28$. During baseline, numbers of episodes of incontinence per day were (mean- $1.48 \pm$ SD-0.5) and after 08 weeks with drug were (Mean- $0.49 \pm$ SD- 0.24) with a mean decrease of $(0.99 \pm 0.56)$ episodes of incontinence per day. There was mean increase of urine voided /micturition $(\mathrm{ml})$ $(45.31 \pm 13.15)$ considering the baseline amount of urine voided /micturition as (Mean- 166.83 \pm SD- 7.52) $\mathrm{ml}$ and amount of urine voided /micturition after 08 weeks of treatment was (Mean- 212.14 \pm SD- 11.66) ml. Baseline values for numbers 
of micturition per day, numbers of episodes of incontinence per day and amount of urine voided /micturition $(\mathrm{ml})$ were significantly different when compared to findings on 08 weeks follow up (Table 3).

In our study (Figure 1) 70 patients experienced mild form of side effects like dry mouth $(42.5 \%)$ headache $(6.25 \%)$ fatigue (7.5\%) constipation $(2.5 \%)$ dysuria $(8.75 \%)$ dizziness $(2.5 \%)$ abdominal pain $(6.25 \%)$ dyspepsia $(8.75 \%)$ and visual disturbance $(2.5 \%)$. There were no moderate or severe level side effects had been reported by the patients.

In response to commenting on perceived benefit of the treatment $09(11.25 \%)$ patients reported that they were not benefited from treatment, while $23(28.75 \%)$ patients experienced little benefit and most of the patients, $48(60.0 \%)$ were subjected to much benefit (Figure 2).

Table 1: Age distribution of the patients based on sex $(n=80)$

\begin{tabular}{|c|c|c|c|c|c|}
\hline & & Gro & Statisti & & \\
\hline & Sex & $\mathrm{n}$ & Mean & Std. Deviation & p value \\
\hline Age of the patients & Male & 19 & 50.89 & 8.445 & 0.687 \\
\hline & Female & 61 & 51.74 & 7.780 & \\
\hline
\end{tabular}

* $\mathrm{p}$ value calculated by t-test

Table 2 : Findings on clinical examination of patients.

\begin{tabular}{lr} 
Clinical Examinations & \multicolumn{1}{c}{$\begin{array}{c}\mathbf{n} \mathbf{8 0} \\
\text { Mean } \pm \text { SD }\end{array}$} \\
Heart Rate (Per minute) & $86 \pm 11.5$ \\
Systolic BP (mmHg) & $132.75 \pm 16.25$ \\
Diastolic BP (mmHg) & $81.30 \pm 10.52$ \\
BMI $\left(\mathrm{Kg} / \mathrm{m}^{2}\right)$ & $25.76 \pm 2.51$ \\
\hline
\end{tabular}

Table 3 : Number of micturition/day, incontinence/day and urinary volume/micturition at Baseline and at 08 weeks follow up. $(n=80)$

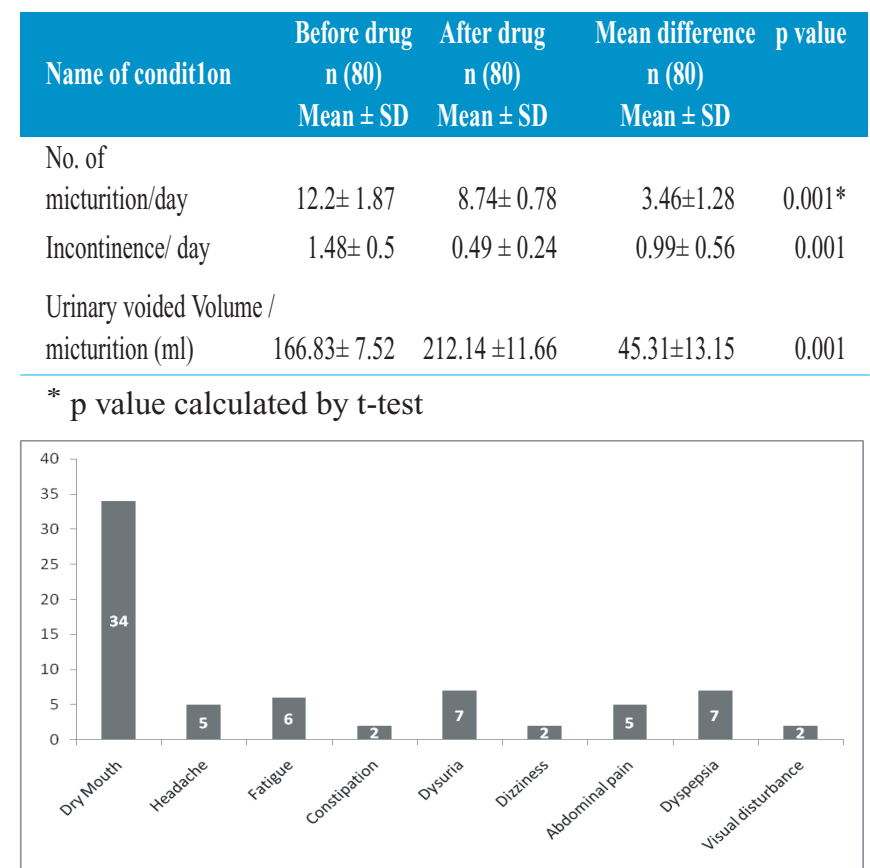

Figure 1 : Bar diagram showing side effects with Tolterodine $(\mathrm{n}=80)$

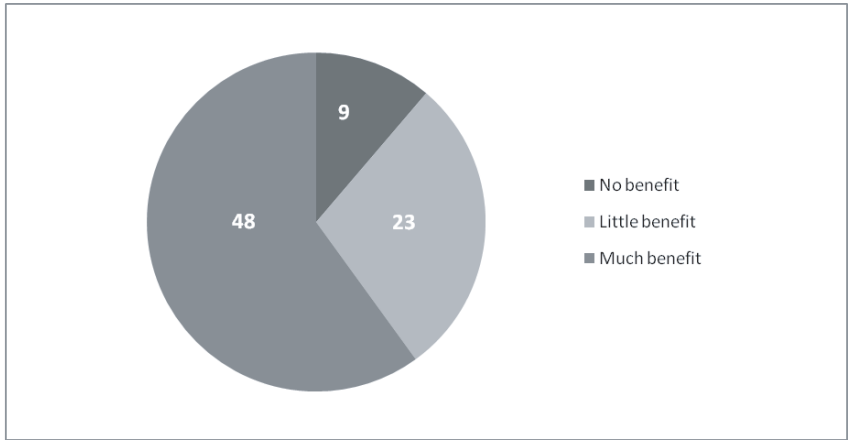

Figure 2 : Perception on treatment benefit of the patients with Tolterodine $(\mathrm{n}=80)$

\section{DISCUSSION}

This observational study was carried out with an aim to evaluate the efficacy and safety of Extended Release tolterodine (ER) to assess the extent of symptoms by keeping bladder diary, to determine the changes of symptoms after 08 weeks with tolterodine and to note any adverse effect associated with the drugs.

A total of 80 patients age ranged from 37 to 65 years complaining at least an episode of urinary incontinence/day were evaluated considering the selection criteria. The male: female ratio was observed as 1:3.2 which is similar to other studies $^{16,17}$. Age of male was (Mean- $50.89 \pm$ SD- 8.44) and age of female was (Mean-51.74 \pm SD- 7.78) which was lower in mean and range in comparison to findings of another study as observed $61.2 \pm 11.8$ years with ranged from 29 to 84 years may be due to wider range of age and including older subjects ${ }^{18}$.

On clinical examination mean heart rate was found 86 per minute and SD was 11.5 per minute. Systolic blood pressure found to be (Mean- $132.75 \mathrm{~mm}$ of $\mathrm{Hg} \pm \mathrm{SD}-16.25 \mathrm{~mm}$ of $\mathrm{Hg}$ ) and diastolic blood pressure was (Mean- $81.30 \mathrm{~mm}$ of $\mathrm{Hg} \pm$ SD- $10.52 \mathrm{~mm}$ of $\mathrm{Hg}$ ). There was an average episode of incontinence more than once a day with an average volume of $166.83 \mathrm{ml}$ of urine per day. The findings were altered with administration of tolterodine (ER) for following 08 weeks. On a follow up after 08 weeks the mean values for no. of micturition/day, incontinence/ day and urinary voided volume/micturition $(\mathrm{ml})$ were $8.74, \quad 0.49$ and 212.14 respectively. Observed efficacies of tolterodine (ER) in some other studies were compatible with our findings ${ }^{19,20,21}$.

The study revealed that the most of the patients, $48(60.0 \%)$ were subjected to much benefit followed by $23(28.75 \%)$ patients experienced little benefit and 09 (11.25\%) patients with no benefit from the treatment. Figure 1 showed mild form of side effects experienced by 70 patients including dry mouth $(42.5 \%)$ headache $(6.25 \%)$ fatigue $(7.5 \%)$, constipation $(2.5 \%)$ dysuria $(8.75 \%)$ dizziness $(2.5 \%)$ abdominal pain $(6.25 \%)$ dyspepsia $(8.75 \%)$ and visual disturbance $(2.5 \%)$. In this regard, the present study findings were closely resembled with a lower percentage of side effects in earlier studies ${ }^{11,19,20}$. No moderate or severe level side effects had been reported by the patients. 


\section{LIMITATIONS}

The study was done on a small number of patients in a single center within a short period of time without urodynamic study. Any conclusion regarding efficacy and safety may be seriously biased by the patients of investigator's knowledge of which treatment was given. No control arm was included to account for possible placebo effect. Patients were asked to comment on each possible side effect, which might have caused overreporting.

\section{CONCLUSION}

After tolterodine (ER) therapy all patients showed improvement in reduced number of micturition per day, decreased number of incontinence per day and increased amount of urine voided in each micturition. It was also found to be highly tolerated with less and mild adverse effects with a satisfactory level of patients compliant.

\section{DISCLOSURE}

All authors hereby declare no competing interest.

\section{REFERENCES}

1. Abrams PA and Wein AJ: Introduction: Overactive bladder and its treatments. Urology. 2000; 55:1-2.

2. Andersson K_E, Arner A, Urinary bladder contraction and relaxation; physiology and pathophysiology. Physiol Rev. 2004; 84:935-986.

3. Tunuguntla H, Narayan P: Changing concepts in diagnosis and Management of Overactive bladder. Clinical Geriatrics. 2001; 2.

4. Abrams P, Kelleher CJ, Kerr LA, and Rogers RG: Overactive bladder significantly affects quality of life. Am J Managed Care. 2000; 6 (Suppl): S580-590.

5. AHCPR Urinary, incontinence in adults guideline update panel: Managing acute and chronic urinary incontinence, Am Farm Phys. 1996; 1661-1671

6. Khoury JM: Urinary Incontinence. No need to be wet and upset. NCMJ. 2001; 62(2) : 74-77.

7. Hallen B and Nilvebrant I: Tolterodine: A new bladder selective muscarinic receptor antagonist: preclinical pharmacological clinical data. Life Sci. 1997; 60: 1129-1136.

8. Stahl MMs, Eckstrom B, Spraf b: Uroynamic and other effects of tolterodine: A novel antimuscarinic drug for the treatment of detrusor overactivity. Neurol Urodynam. 1995;14: 647-655.

9. Brynne N, Stahl MMS, Hallen B: Pharmacokinetics and pharmacodynamics of tolterodine in men. A new drug for the treatment of urinary bladder overactivity . Int J Clin Phamacol Ther. 1997; 35:287-295

10. Abrams P, Freeman R, Anderstrom C, Mattiason A: Tolterodine, a new antimuscarinic agent : As effective but better tolerated than oxybutynin in patients with an overactive bladder. Br J urol. 1998; 81:801-310

11. Millard R, Tuttle J, Moore K, Susset J , Clarke B, Owyer P: Clinical safety and efficacy of tolterodine compared to placebo in einuor overactivity. J Urol. 1999; 161(5): 1551-1555.

12. Chancellor M, Freedman S, Mitcheson HA : Tolterodine, an effective and well tolerated treatment for urge incontinence and other overactive bladder symptoms. Clin Drug Invest. 2000; 19:83-91

13. Rentzhog L, Stanton SL, Cardozo L, Nelson E, Fall M, Abrams P: Efficacy and safety of tolterodine in patients with detrusor instability, a dose-ranging study. Br J Urol. 1998; 81:42-48.

14. Ruscin JM, Morgenstem NE: Tolterodine use for symptoms of overactive bladder. Ann Pharmacother. 1999; 33: 1073-1082,

15. Crandall C: Tolterodine; A clinical review. J Women Health \& Gender- Based Med. 2001; 10(8): 735-743.

16. Milsom I, Abrams P, Cardoza L: How widespread are the symptoms of overactive bladder and how are they managed ? A population -based prevalence study. BJU Int. 2001; 87:760-766.

17. Abrams P, Malone -Lee J, Jacquetin B, Wyndaele JJ, Tammela T, jonas U, Wein A: Twelve-month treatment of Overactive bladder: efficacy and tolerability of tolterodine. Drugs Aging. 2001; 18(7): 551-560.

18. Homma Y, Paick JS, Lee JG, Kawabe K: Clinical efficacy and tolerability of extend release tolterodine and immediate release oxybutynin in Japanese and Korean patients with an overactive bladder : A randomized placebo controlled trial . BJU Int. 2003; 92(7) : 741-747.

19. Malone-Lee J, Shaffu B, Anand C, Powell C: Tolterodine: Superior tolerability than and comparable efficacy to oxybutynin in individuals 50 years old or older with overactive bladder. J Urol. 2001: 165(5): 1452-1456.

20. Homma Y, Paick JS , Lee JG, Kawabe K: Clinical efficacy and tolerability of extend release tolterodine and immediate release oxybutynin in Japanese and Korean patients with an overactive bladder : A randomized placebo controlled trial. BJU Int. 2003; 92(7) : 741-747.

21. Kerrebroeck PV, Kreder K, Jonas U, Zinner N, Wein A : Tolterodine once daily: superior efficacy and tolerability in the treatment of the overactive bladder. Urology. 2001; 57:414-421. 